\title{
Construction of Humanistic Silk Road with Sharing Cultures and Intercommunicating Souls Based on Chinese Civilization Wisdom
}

\author{
WEI Li \\ Liaoning Police Academy, Dalian, China
}

\begin{abstract}
The silk is the symbol of China and ancient Chinese culture; the Silk Road is not only the business and trade road, but also the civilized and open road with cultural exchange and intercommunication. In the long course of human history, the Silk Road has been always regarded as the bright cultural corridor connecting China and Western Regions, South Asia, and even European continent. In the new era, China contributes the fresh design of One Belt One Road to the world in order to cope with global economic recession, environmental degradation, terrorism threat, and regional conflicts. One Belt One Road intends not only to remind the people along the Silk Road of those old golden times of economic prosperity and cultural exchange, but also to propel global economic recovery through increasing driving force of cooperative economic development, establishing the new global economic system. This Chinese specific design embodies Chinese civilization wisdom making the point of Benevolence and Harmony, Unity of Man and Nature, Inclusive Development, Tolerance and Coexistence. In this complex and contradicting world, the Chinese wisdom is the super alternative to defuse tension and promote harmony. In order to construct the humanistic silk road, the author proposes the following measures: Culture Priority" Strategy, Go Out policy of Chinese cultures, widespread of Chinese civilization wisdom, the continual development of Confucius Institutes in the countries along the Silk Road and other countries relevant to it, opening multi-languages training schools in China and other Silk Road countries depending on Silk Road Multi-languages Organization, Establishing the Silk Road O-2-O Multicultural Forum and Holding the Annual Silk Road Carnival by Turns. The Silk Road is indeed a cultural road connecting and enriching people's social lives and spiritual lives.
\end{abstract}

Keywords: The Silk Road, Chinese civilization wisdom, cultural effect, "Culture Priority" strategy, soul-to-soul intercommunication, OBOR

\section{Introduction}

Over the course of the Chinese history, there appeared the brilliant rays of silk long ago. In fact, silk is much older than four great inventions of ancient China, [1] according to the editors of History of Silk in History of Chinese Civilization. As the vital symbol of Chinese history and culture, silk has been interpreted as the synonym for China. The splendid silk won the elegant honor of Silk Country for China. It was not only the significant creation in ancient China, but also the close representation of Huaxia Culture.

From Chang'an (the capital of Tang Dynasty) to the European continent, the civilizations of East and West were integrated and interacted for thousands of years. Today, the Silk Road Economic Belt endowed with the brand-new significance is flourishing with vigor and vitality. Since the proposal of One Belt One Road was put forward by president Xi Jinping three years ago, the cooperative blueprint of OBOR has been portrayed bit by bit from point to surface, and even nearly from scratch. The proposal of OBOR is not the Marshall Plan, not the wild ambition of governing other countries, but the pragmatic development project highlighting the Chinese wisdom of inclusive development on the basis of the human common destiny and the fresh thinking on constructing the new global governing order. It is bound to inject new impetus to global economic recovery and long-term stable and harmonious development.

\section{Retrospection of Ancient Silk Road and Cultural Reflection on Its Influence}

\subsection{The historic retrospection of the Silk Road}

In 1926, Tsinghua archeological team digged out a silkworm cocoon in half in Yangshao culture sites, which provided the sound evidence that China is the origin of silk, dating back to 4000 and 3000 BC. In 1958, the silk fabrics were found in Qingtai sites of Zhejiang and Henan provinces. This archeological discovery bridged the gap that there wasn't silk in Central China in Neolithic Period, pushing the time of making and using silk in China 1000 years backward. Another discovery of silk ribbon and silk yarn and in Qiansanyang culture sites was in 2750 BC, 200 years earlier than the legend of Silk Goddess (Luozu as the wife of Yellow Emperor, also the Mother of Chinese nation, was regarded as Silk Goddess). Professor Valerie Hansen of Yale University once claimed that Chinese nation is really the first nation to make silk, and the most reliable evidence is Chinese characters. Only the Chinese can weave them in their silk fabrics. [2] 
Ancient Silk Road: according to the ancient document literature, the Chinese communication with Central Asia and beyond can date back to Zhan Qian's travel to western countries. But according to research, East-West trade with the silk as the main mark had long history of several thousands of years, earlier than Zhang Qian's travel. Around four thousands of years ago, Chinese silk was sent to Europe.

During the periods of Han and Jin Dynasties, the Silk Road promoted the increase in population and development in economy. Central Plain Culture, foreign cultures and native cultures were integrated organically, creating the new prospect active minds, cultural progress and arts flourishing, which added the brilliance and splendor to Chinese cultural treasure. When it turned to Sui and Tang Dynasties, with the country's unity, the economy's developing and the open policy to the world, East-West intercommunication between material and culture became comprehensive, and the Silk Road was flourishing as never before. In the era of agricultural civilization as the main economic pattern, the trade between China and Central Asia rose to the new level: cities in the Near East and Central East could purchase Chinese commodities; the trade shares of China and foreign countries accounted for 5\% of Chinese economy. But An Lushan Rebellion became the key declining point of Chinese overland Silk Road, symbolizing the end of prosperity of the Silk Road since Han Dynasty.

There's no exact time of the rise of the Silk Road trade on the sea. But after the fall of the Han Dynasty in 220 A.D., the sea way from the Indian Ocean to the Red Sea was open, so the silk trade for Roman Empire reverted to the sea way gradually. In this sense, the ancient Sea Silk Road began from the Western Han Dynasty. It's hard to say that the Sea Silk Road was opened by which country. It experienced the progressive process from point to point, from far to near, and from the poor technology in shipbuilding and navigation to the better. Zheng He's traveling to the west in Ming Dynasty attained the heyday of Chinese navigational trade in such aspects as scale, distance, scope and traded items, which also extended the route scope of the Sea Silk Road. However, with the maritime embargo policy in Ming and Qing Dynasties, the Sea Silk Road was cut off, which was resulted from the centralized ideas of feudal system, and also the embodiment of encouraging agriculture rather than trade.

\subsection{The cultural effect of the Silk Road}

The silk is not only the product for trade contact, but also the link for cultural exchange. With the prosperity of the Silk Road, the artistic forms, such as music and dance from Central Asia and India, was firstly introduced to Sinkiang and Hexi District of Gansu Province. After the integration into the local music and dance, the Qiuci Music and Xiliang Music with beautiful rhythms and whirling dances were formed. Furthermore, they became the foundation of court dance in Sui and Tang Dynasties, spreading to Korea and Japan later on.

The first cultural convergence of home and abroad can trace back to the periods of Han and Tang Dynasties. What they absorbed was mainly the cultures from the Western Regions (Central Asia and Western Asia) and also the South Asian Sub-continent. [3] The absorbed cultural content is Buddhist philosophy. It is generally believed that it was in 67 A.D. that the Buddhism was introduced to China formally. In the developing process of Buddhism in China, the Chinese remolded the Buddhist philosophy while digesting its essence, integrating Chinese traditional Confucianism into it tactfully. Owing to the wide diffusion of Buddhism, many cultural aspects in China were influenced profoundly. Arts in Tang Dynasty got to rich and colorful thanks to absorption of Buddhist culture. The painters of Sui and Tang Dynasties absorbed the soul from rich Buddhist paintings in religious theme, greatly improving their national painting skills and expressive forces. Chinese grotto arts are the perfect palace to appreciate Chinese ancient Buddhist arts. Those Buddhist statues varied in expressions and postures; those religious murals were brimmed with high spirits; those calligraphies were full of vitality. All of these artistic attainments achieved unprecedented maturity and perfection. The golden time of Chinese culture is in the Han and Tang Dynasties, and one of its main reasons is massive absorption of foreign cultures from the Western Regions and the South Asian Sub-continent.

The Silk Road is not only the commercial and trade road and cultural corridor, but also the civilized and open road. Its history is the history of friendly communications between ancient China and the world, which reflects the truth: only opening up and drawing on other successful experiences can promote human being's civilization. The mutual learning from other cultures among different ethnicities around the world is the essential feature of human civilization, and the crucial impetus to develop civilization. The challenge for us to face is how to cope with the relationships between different cultures and how to promote mutual learning from other cultures to attain common improvement. [4] 


\section{Construction of Humanistic Silk Road with Sharing Cultures and Intercommunicating Souls on the Basis of Chinese Civilization Wisdom \\ 3.1 "Culture Priority" Strategy: Go Out policy of Chinese cultures and wide spread of Chinese civilizations wisdom in constructing $\mathrm{OBOR}$}

Go Out Policy of Chinese cultures: The civilization is the accumulation of human brilliant cultural achievements, which contributes to creating harmonious atmosphere. The civilization communication motivates the creative force to make the world go around smoothly. China, as one of the Four Great Ancient Civilizations, possesses long-standing and glorious cultures and admirable civilizations. In the process of boosting the developing pace of One Belt One Road, the Chinese is responsible for spreading Chinese civilization, for it is the preface to promote the re-development of the world civilization.

Go Out policy of Chinese culture is a process to spread civilization including witnessing, expanding and enriching civilization with concrete words and actions. [5] The radical motive of advocating Go Out policy is the historic law of mutual civilization communication and reference. According to the understanding of our practice, Chinese cultures' going out doesn't mean assimilating other people, but rather, sharing with others, integrating and developing. In the process of mutual learning and absorbing, let's make world civilizations prosperous and progressive collectively. As a result, the maintenance of harmonious coexistence and integrative development between Chinese nation and other nations is our supreme goal and tenet.

Wide spread of Chinese civilization wisdom: Ancient Chinese philosophies, especially Confucianism, have been disseminated overseas for centuries. Voltaire, the Enlightenment leader and tutor, once said: "I read Confucius' masterpieces absorbedly, taking in the best of them. -------The happiest and the most respectable time that we ever had on this earth is the time to obey the Confucius' laws and regulations." With the implementation of reform and open up policy, Confucianism turned to the highlight of sinology study in overseas. As American sinologist Stephen [6] expressed: "Confucianism is not only a closed cultural system relevant to China, but it is, on the contrary, an open and global philosophy which is relevant to China and also to America. Confucianism education is most important for us to understand our world and experience. Whether in history or at present, Confucianism plays different roles in our daily lives. It influences and guides children education, government's making policies, religious rites, and individual psychological needs in various forms. Through higher evaluations from the past and present philosopher and scholar, we can see the great charm and values that Confucianism possessed with its lasting vitality and philosophical ideas.

In order to examine and understand the Chinese philosophy and wisdom, it's necessary to make a reasonable comparison between Chinese and Western cultures.

\begin{tabular}{|c|c|c|}
\hline & Chinese cultures & Western cultures \\
\hline $\begin{array}{l}\text { As to the relationship } \\
\text { between man \& nature }\end{array}$ & $\begin{array}{l}\text { Unity of Man and Nature; the harmonious } \\
\text { relationship }\end{array}$ & Conquest of nature; the contradicting relationship \\
\hline As to the war \& peace & Introverted; defensive; pen first; tolerance & $\begin{array}{l}\text { Extroverted, aggressive; sword first; } \\
\text { intolerance }\end{array}$ \\
\hline As to the family matters & Family-oriented values & Individual-based values \\
\hline As to the national relations & $\begin{array}{l}\text { Loving people and treating neighbors } \\
\text { kindly; friendly coexistence }\end{array}$ & $\begin{array}{l}\text { Conquest of the world; competition and } \\
\text { coordination }\end{array}$ \\
\hline Core Values to uphold & $\begin{array}{l}\text { Filial piety; sense of hierarchy; } \\
\text { collectivism; responsibility and duty in the } \\
\text { group; less time consciousness and } \\
\text { present-orientation }\end{array}$ & $\begin{array}{l}\text { Freedom, equality and fraternity; individualism; } \\
\text { democracy; materiality; time consciousness and } \\
\text { future-orientation }\end{array}$ \\
\hline Awareness emphasis & unity and coordination & Independence and creativity \\
\hline
\end{tabular}

Table 1: The comparative study of Chinese \& Western cultures

According to the above comparison, we can make certain that Chinese traditional value orientations are more suitable than Western ones to tackle the present global problems in economic crisis, national contradictions, political differences, cultural conflicts, environmental pollutions, energy crisis, and development distress. Undoubtedly, there are advantages and disadvantages as to Chinese and Western cultures, but in the modern era and under the intricate international situation, to select Chinese philosophy characteristic of Confucianism to settle the current global affair is the superior alternative.

Chinese traditional cultures are broad and profound filled with philosophical essence of countless philosophers and educators. They advocate peace and harmony, while oppose the abuse of force; they pursue attraction and approval, while object to coercion and high tension. Confucianism stressed that in the actual practice of propriety, flexibility is important, which means keeping harmonious relationship is the optional policy for the king or other directors. Mo-tse also upheld the idea of non-offence through loving each other and benefiting each other. Chinese abide by the principle relevant to the war: to take the pen first and then the sword; to choose the good pretext for waging a war. [7] All these prudent attitudes toward the war offer the modern presidents or potentates the best revelations and warnings: this is a world of love and peace, and any person or 
any means to destroy the peace and harmony will deviate from the well-balanced orbit of Rules of Living. A just cause enjoys abundant support, while an unjust cause finds scant support. As present responsible leaders of major or minor countries, they should pursue just causes rather than unjust ones, for justice and equality are bound to win over power and violence, leading to the natural construction of harmonious and peaceful coexistence and mutual development. The Chinese civilization wisdom can promote the new round of global vigorous progress with benevolent administration, cooperative development, tolerant mutual accommodation, and common prosperity.

\subsection{The construction of diversified cultural projects to realize soul-to-soul intercommunication: to build the bridge and platform for language understanding and cultural integration}

The continual development of Confucius Institutes in the countries along the Silk Road and other countries relevant to it: Confucius Institutes as the bridge towers to spread Chinese traditional cultural essence have been established in countless countries. According to the Annual Development Report of Hanban in 2015, by the end of 2015, there had been 500 Confucius Institutes and 1000 Confucius Classrooms with a total of 1,900,000 registered students in 135 countries. [8] The latest report from the forum of One Belt One Road 100 states that there have been 11 Confucius Institutes in Central Asia and the number of registered students is rising rapidly. The student Aynur from Confucius Institute of Eurasia University said: "nowadays a lot of people are talking about the Silk Road. I thought it was the elapsed ancient history, being far away from me. But now I find it is close to me, for we have more chances to learn Chinese, to visit China, and to obtain good jobs in KZ. In my point of view, this is a win-win measure." [9] Chinese cultures have been learned and understood gradually through learning Chinese and experiencing Chinese cultural forms, which facilitates more and more foreigners to know, to be familiar with, and then to appreciate Chinese philosophy and thinking styles so as to promote clear soul-to-soul intercommunication among the people regardless of races, nationalities, religions, or cultural backgrounds. Owing to the implementation of One Belt One Road proposal, more and more foreigners, especially the young people, are paying close attention to Chinese enterprises and Chinese language. Through learning Chinese they begin to approach Chinese traditional cultures including Chinese music and dance, arts and architecture, cooking and eating, painting and calligraphy, education and literature, and etc. The more they learn about Chinese language and cultures, the more they love and appreciate China and Chinese people. This is the charm of cultural learning and communication. Much ignorance and misunderstanding about China and Chinese will be cleared away thoroughly, and one the contrary; much appreciation and in-depth understanding about this mysterious and rising country will be increased and reinforced comprehensively. This favorable tendency should be maintained and developed continually. Apart from adding Chinese teaching resources from inland, Confucius Institutes can also utilize the local human resources, selecting those local "masters of language" to enrich Chinese teaching team. This strategy can not only decrease the financial burden and teaching resources allocation, but also increase the driving force to encourage the local people to become the backbone of teaching team who can serve as the good examples to follow.

Here we should bear it in mind that the establishment of Confucius Institutes doesn't mean assimilating other people, but sharing with others to attain the goal of integration and development with the same aspirations. In the process of mutual learning from each other and absorbing diversified cultures, the civilization will obtain common prosperity and progress. As a result, the ultimate goal of Confucius Institute is to promote national understanding and spiritual intercommunication to reach the harmonious coexistence and common development through spreading and sharing Chinese traditional cultures.

Opening multi-languages training schools in China and other Silk Road countries depending on Silk Road Multi-languages Organization: language is the cornerstone of culture; the mastery of language is the first step to approach culture. Confucius Institutes only enable foreigners to learn Chinese, but, as the Chinese, we cannot approach other cultures if being ignorant of other languages. In this sense, only the establishment of Confucius Institutes is not enough, so we should advocate opening multi-language training school in most of the countries along the Silk Road. We propose that all languages that the Silk Road countries speak except minimal language should be involved in order to embody cultural equality. In view of the difficulties to collect abundant multi-languages teachers, the author proposes to establish Silk Road Multi-languages Organization in charge of collecting teaching resources, training and building teaching teams, selecting and dispatching qualified language teachers to different training schools. This organization is a non-governmental one with independent functions in finance and operation, but it needs support and cooperation from different educational institutions in terms of providing suitable language teaching resources. It has to contact various governments to set up suborganizations in these countries to ensure the proper operation of Multi-languages training schools. Languages along the Silk Road tend to be non-general languages, and if we don't adopt special policy or measure, these languages are always grossly underemphasized. So this positive language strategy can promote the popularity of multi-languages of the Silk Road countries, in particular, those remote and alien countries. This organization is a collaborative structure with multilateral participation and contribution in linguistic and educational study. 
Establishing the Silk Road O-2-O Multicultural Forum and Holding the Annual Silk Road Carnival by Turns: The youth is the bright future of our earth, so it's preferable to establish the Silk Road O-2-O Multicultural Forum mostly among youth from the Silk Road countries. This online and offline cultural communication platform takes full advantage of information technology, transferring the immediate sparks of thought to others in different space. This soul-to-soul dialogue at any time is the superexcellent approach to enhance mutual understanding and trust. The multicultural forum emphasizes exchange of higher-leveled thoughts and in-depth thinking from different cultural backgrounds, while the Annual Silk Road Carnival is characteristic of sharing concrete multicultural forms including folk arts and music, culture-oriented travel, various cultural experience, etc. This multicultural gathering is held by different Silk Road countries annually by turns, and the host country will display its traditional and modern cultural treasure and feature in all dimensions to the overseas participators. The Annual Silk Road Carnival is a visualized exhibition of the culture, which makes the outsiders approach an alien world, getting to familiar with it and then falling love with it ultimately. This is a strange cultural journey full of surprise, rejoice, excitement, and contentment. This is a true process of cultural experience bringing us enormous spiritual satisfaction and emotional enjoyment. In fact, the ultimate goal of soul-to-soul intercommunication will be realized along with the successful cultural journey.

\section{Conclusion}

"Go Out" of Chinese culture is a process of spreading Chinese civilization, which involves witnessing civilization with concrete words and deeds, enriching civilization, developing civilization, making views of civilizations integrate into all subjects. We do hope that people's souls will have conscious relations with civilization, and thus build harmonious interactions with all living things on earth. [10] The intrinsic connotation of One Belt One Road is interconnection and intercommunication in which "Soft Intercommunication" attaches greater importance to communication and exchange in terms of language, culture, spirits and values. In essence, the soul-to-soul intercommunication is the highest level of intercommunication, but the most difficult one to achieve. [11] After three years' design and implementation, One Belt and One Road has stepped in the fast-track stage, comprehensive cooperation advancing steadily and effectively in infrastructure construction, energy development, agricultural development, and telecom management. The above "Hard Interconnection" brings about concrete profits to the Silk Road countries, but we have to focus on "Soft Intercommunication" at the back of "Hard Interconnection", for it is the support, and the guarantee to ensure the long-term and steady cooperation without misunderstanding and suspicion. One Belt and One Road doesn't only intend to seek business opportunity and build business connections, but also construct the community of destiny on the basis of multicultural, working on getting through cultural traditions and sharing values. [11]The Silk Road is indeed a cultural road connecting and enriching people's social lives and spiritual lives. The design and implementation of One Belt One Road should adhere to the principle: business cooperation is based on cultural understanding; the cultural consciousness promotes the sustainable progress of business strategy; the mutual trust in culture can bring about lasting peace and prevailing prosperity.

\section{Acknowledgement}

The research is financed by the Thirteenth Five-year Plan for Educational Science Project of Liaoning Province (2016) No.JG16DB213: A Study on Standard Model of FCM of EGP with Chinese Cultural Specialty.

\section{References}

[1] Editorial board. History of Silk of History of Chinese Civilization, Beijing: Encyclopedia of China Publishing House, 2010.

[2] Fu Mengzi. Re-examining the Origin and Evolution of the Ancient Silk Road. From http://www.obor100.com/, 2017-01-25.

[3] Baidu Wenku. Silk Road and Cultural Exchange. From http://blog.sina.com.cn/s/blog_8dfa9ca20101ouw0.html, 2017-02-19.

[4] News Agency. Looking back at three years' achievements of One Belt One Road.

From http://www.scio.gov.cn/ztk/wh/slxy/31200/Document/1493006/1493006.html, 2016-10-08.

[5] Stephen C. Angle. How to understand the Rise of Chinese Culture.

From_http://kongzi.dzwww.com/tt/201611/t20161103_15097584.htm, 2016-11-03.

[6] Lou Xiaoqi. One Belt One Road Needs Chinese Cultures Going Out. From http://www.jiupaicn.com/2016/1221/269643.html, 2016$12-21$.

[7] Zhao Guangcheng. Perspective on Chinese Soft Power under the Background of One Belt One Road. From http://www.obor100.com/, 2017-01-6.

[8] Confucius Institute Annual Development Report. From http://www.hanban.edu.cn/report/2015.pdf, 2017-02-23.

[9] Confucius Institutes on the Silk Road. From http://www.obor100.com/, 2017-02-21.

[10] Lou Xiaoqi. One Belt One Road Needs Chinese Cultures Going Out. From http://www.jiupaicn.com/2016/1221/269643.html, 201612-21.

[11] Zhao Lei. "Soft Intercommunication" of One Belt One Road: Working through Cultural Tradition and Sharing Values. From http://news.youth.cn/gn/201701/t20170103_9007598.htm, 2017-01-03. 